\title{
Comunicação
}

[Communication]

\section{Ocorrência de Trypanosoma vivax no estado de Minas Gerais}

[Occurrence of Trypanosoma vivax in Minas Gerais state, Brazil]

\author{
A.U. Carvalho ${ }^{1}$, D.C. Abrão ${ }^{2}$, E.J. Facury Filho ${ }^{1}$, P.R.O. Paes ${ }^{1}$, M.F.B. Ribeiro ${ }^{2 *}$ \\ ${ }^{1}$ Escola de Veterinária - UFMG \\ ${ }^{2}$ Instituto de Ciências Biológicas - UFMG \\ Caixa Postal 486 \\ 31270-910 - Belo Horizonte, MG
}

Trypanosoma vivax ocorre na Ásia e África, onde é transmitido ciclicamente por moscas tsétsé (Glossina spp.) (González et al., 2005; Batista et al., 2007), e na América do Sul, América Central e algumas ilhas do Caribe, onde é transmitido mecanicamente por outras moscas hematófagas (Meléndez et al., 1993; Batista et al., 2007). No Brasil, T. vivax já foi descrito nos estados do Pará (Boulhosa, 1946; Shaw e Lainson, 1972), Amapá (Serra-Freire, 1981), Mato Grosso (Silva et al., 1996), Mato Grosso do Sul (Paiva et al., 1997; Barbosa Jr. et al., 2001) e Paraíba (Batista, et al., 2006).

Os impactos econômicos causados por esta tripanosomíase estão relacionados com a queda na produção, associada ao amplo espectro de vetores e hospedeiros susceptíveis, e à imunodeficiência dos animais, em sua maioria subnutrida (García et al., 2006). Os sinais clínicos incluem anemia, febre, letargia, perda progressiva de peso, queda na fertilidade e produção de leite e de carne, aborto, agalaxia e, eventualmente, morte (Delafosse et al., 2006).

Em agosto de 2007, uma vaca proveniente de propriedade rural do município de Igarapé - MG, apresentando perda da visão foi encaminhada ao Hospital Veterinário da Escola de Veterinária da UFMG. No exame clínico foi constatado que o animal se apresentava anêmico e com baixo escore corporal. Ao realizar-se o hemograma, constatou-se presença de protozoários flagelados na forma de tripomastigota, tendo sido dado o diagnóstico de Trypanosoma sp.

Amostras de sangue deste animal foram colhidas em tubos vacutainer contendo anticoagulante EDTA. Uma parte da amostra foi criopreservada em nitrogênio líquido e a outra utilizada na confecção de esfregaços sangüíneos, os quais foram corados pelo método Panótico Rápido. Estudos morfológicos e morfométricos (Hoare, 1972) foram realizados com 50 tripomastigotas observadas em microscópio óptico sob imersão, fotografadas e, posteriormente, foram realizadas as medições pelo programa Image Pro Plus versão 4.51 .

As formas tripomastigotas observadas apresentavam extremidade posterior arredondada, membrana ondulante fracamente desenvolvida, núcleo central e cinetoplasto terminal, característicos de T. vivax (Hoare, 1972) (Fig. 1). Mediram-se as distâncias entre o final da extremidade posterior e o cinetoplasto; o cinetoplasto e o meio do núcleo; o meio do núcleo e o final da extremidade anterior e os comprimentos do flagelo livre e do parasito. Os índices nuclear $(\mathrm{N} . \mathrm{I} .=\mathrm{PN} / \mathrm{NA})$ e cinetoplástico $(\mathrm{K} . \mathrm{I} .=\mathrm{PN} / \mathrm{KN})$ foram utilizados para definir a posição do núcleo e do cinetoplasto no parasito. Os resultados obtidos da mensuração dos parasitos assemelham-se a de outros isolados de T. vivax descritos em outros estados brasileiros (Tab. 1), o que confirma o diagnóstico morfométrico.

Recebido em 2 de janeiro de 2008

Aceito em 30 de maio de 2008

*Autor para correspondência (corresponding author)

E-mail:muciobr@icb.ufmg.br 
Tabela 1. Comparação entre as médias biométricas $(\mu \mathrm{m})$ do Trypanosoma vivax isolado de Igarapé, $\mathrm{MG}$ e outros isolados no Brasil

\begin{tabular}{lcccccccc}
\hline & L & PK & KN & PN & NA & F & KI & NI \\
\hline Minas Gerais (2007) & 19,89 & 0,90 & 6,64 & 7,55 & 7,46 & 6,22 & 1,04 & 1,14 \\
Pará (Shaw e Lainson, 1972) & 22,77 & 0,65 & 6,16 & 7,60 & 8,22 & 6,92 & 1,23 & 0,94 \\
Mato Grosso (Silva et al., 1996) & 18,73 & 1,02 & 6,10 & 7,18 & 5,40 & 6,15 & 1,17 & 1,50 \\
Mato Grosso do Sul (Paiva et al., 1997) & 18,10 & 0,30 & 7,46 & 7,76 & 6,03 & 4,30 & 1,04 & 1,34 \\
\hline
\end{tabular}

L: comprimento total do parasito, incluindo o flagelo livre; P.K.: distância do final da extremidade posterior ao cinetoplasto; K.N.: distância do cinetoplasto ao meio do núcleo; P.N.: distância do final da extremidade posterior ao meio do núcleo; N.A.: distância do meio do núcleo ao final da extremidade anterior; F: comprimento do flagelo livre; KI: índice cinetoplástico ; NI: índice nuclear.

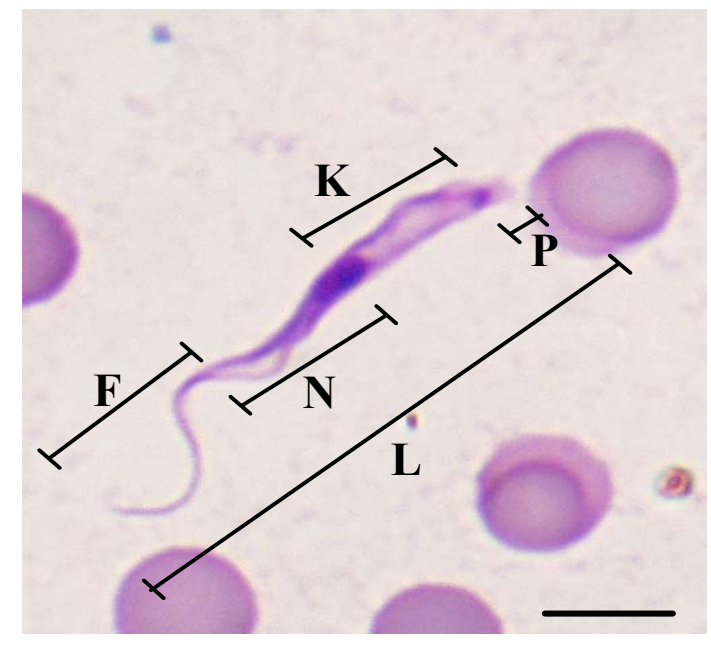

Figura 1. Morfologia e pontos utilizados na morfometria dos Trypanosoma vivax observados em esfregaços sangüíneos de bovino naturalmente infectado, Igarapé - MG, 2007. Barra: $5 \mu \mathrm{m}$.
Até o momento, estudos sobre a ocorrência de $T$. vivax no Brasil vêm sendo conduzidos somente em áreas endêmicas, principalmente no Pantanal. Alguns autores sugerem que T. vivax possua grande potencial de distribuição para outras áreas físiográficas do Brasil, nas quais os vetores estão presentes (Jones e Dávila, 2001; Madruga et al., 2006).

Este é o primeiro relato da ocorrência de $T$. vivax no estado de Minas Gerais. Atualmente está sendo realizada investigação epidemiológica na propriedade problema e nas propriedades vizinhas, para que se possa ter o conhecimento da prevalência e difusão deste tripanosomatídeo na região.

Palavras-chave: bovino, Trypanosoma vivax, tripanosomíase

\section{ABSTRACT}

A cow from Igarapé city, Minas Gerais state, Brazil, showing vision damage was referred at the Veterinary Hospital of the Universidade Federal de Minas Gerais. Clinical examination revealed anemia and a flagellated protozoan was observed in the blood smears obtained from the animal. The morphometric analysis demonstrated that the protozoan was Trypanosoma vivax. This is the first report of T. vivax occurrence in Minas Gerais state. An epidemiological investigation is currently being conducted on the farm and neighbor areas in order to estimate the parasite prevalence and the distribution of this trypanosomiasis in the region.

Keywords: bovine, Trypanosoma vivax, trypanosomiasis

\section{REFERÊNCIAS BIBLIOGRÁFICAS}

BATISTA, J.S.; RIET-CORREA, F.; BARBOSA, R.C. et al. Infecção experimental por Trypanosoma vivax em ovinos. Pesq. Vet. Bras., v.26, p.31-37, 2006.
BATISTA, J.S.; RIET-CORREA, F.; TEIXEIRA, M.M.G. et al. Trypanosomiasis by Trypanosoma vivax in cattle in the Brazilian semiarid: Description of an outbreak and lesions in the nervous system. Vet. Parasitol., v.143, p.174-181, 2007. 
BARBOSA JR., N.S.; MADRUGA, C.R.; OSÓRIO, A.L.A.R. et al. Descrição de surto de tripanossomose bovina por Trypanosoma vivax, com morte perinatal no Pantanal de Aquidauana, MS. In: CONGRESSO BRASILEIRO DE BUIATRIA, 4., 2001, Campo Grande. Anais... Campo Grande, 2001. p.135.

BOULHOSA, J. Informação científica. Rio de Janeiro: Ministério da Agricultura, 1946. p.2126. (Boletim Técnico).

DELAFOSSE, A.; THE'BAUD, E.; DESQUESNES, $M$. et al. Epidemiology of Trypanosoma vivax infection in cattle in the tsetse free area of Lake Chad. Prev. Vet. Med., v.74, p.108-119, 2006.

GARCÍA, H.; GARCÍA, M.E.; PÉREZ, G. et al. Trypanosomiais in Venezuelan water buffaloes: association of packed-cell volumes with seroprevalence and current trypanosome infection. Ann. Trop. Med. Parasitol., v.100, p.297-305, 2006.

GONZÁLEZ, L.E.; GARCÍA, J.A.; NÚÑEZ, C. et al. Trypanosoma vivax: A novel method for purification from experimentaly infected sheep blood. Exp. Parasitol., v.111, p.126-129, 2005.

HOARE, C.A. The trypanosomes of mammals. In: HOARE, C.A. A zoological monograph. classification. Oxford: Blackwell Scientific Publications, 1972. p.60-80.
JONES, T.W.; DÁVILA, A.M. Trypanosoma vivax - out of Africa. Trends Parasitol., v.17, p.99-101, 2001.

MADRUGA, C.R.; ARAÚJO, F.R.; CAVALCANTE-GOES, $G$. et al. The development of an enzyme-linked immunosorbent assay for Trypanosoma vivax antibodies and its use in epidemiological surveys. Mem. Inst. Oswaldo Cruz, v.101, p.801807, 2006.

MELÉNDEZ, R.D., FORLANO, M., FIGUEROA, W. Perinatal infection with Trypanosoma vivax in a calf in Venezuela. $J$. Parasitol., v.79, p.293-294, 1993.

PAIVA, F.; LEMOS, R.A.A.; OSHIRO, E.T. et al. Ocorrência de Trypanosoma vivax em bovinos no estado de Mato Grosso do Sul. Rev. Bras. Parasitol. Vet., v.6, Supl.1, p.349, 1997.

SERRA-FREIRE, N.M. Oiapoque - outro foco de Trypanosoma vivax no Brasil. Rev. Bras. Med. Vet., v.4, p.30-31,1981.

SHAW, J.J.; LAINSON, R. Trypanosoma vivax in Brazil. Ann. Trop. Med. Parasitol., v.66, p.2532, 1972.

SILVA, R.A.M.S., DA SILVA, J.A., SCHNEIDER, R.C. et al. Outbreak of Trypanosomiasis due to Trypanosoma vivax (Ziemann, 1905) in bovines of the Pantanal. Brazil. Mem. Inst. Oswaldo Cruz, v.52, p.561562,1996 